\section{Council of Europe}

In May 1985 a seminar on "Sport and Physical Education in Primary Schools" was held in Bilbao, Northern Spain. Emphasis was placed on the need to fit the programme to the physical and psychological needs of the children, the need for general and PE teachers to appreciate this, in initial or in-service training, and to pay special attention to the less physically gifted. There is need for international collaboration, and for research into the needs of the primary school child (DS-PE (85) 2).

In June, a meeting at Strasbourg was devoted to spectator violence in sport in general, and football in particular. Recommendations made are already largely under discussion in the UK, expedited by the disaster of the Juventas-Liverpool match in Belgium - ticket sales, segregation of supporters ban on weapons and alcohol, and adequate policing (MSL. GT 12 (85) 5 and 6).

\section{FIMS Statement on Doping}

Proposal of the working party of Hollmann, Dirix and Sperryn, July 1983, of a draft statement

FIMS, while recognising the continuing importance of doping control on the eradication of doping practices in sport, expresses concern that the increasing costs of control are being met at the expense of positive sports medical services in relation to the scientific preparation of athletes' health and fitness and facilities for the treatment of their medical and injury problems.

FIMS appeals for new initiatives in education and antidoping propaganda aimed at protecting health by eliminating doping, including the inappropriate use of medicaments, by all sports people.

\section{CCPR Community Sports Leaders Award}

The Central Council of Physical Recreation have asked us to draw attention to this award, available to people wishing to help with sport in the community. It is open to 6th formers and adults up to early middle-age, takes a total of about 25 hours in sessions of seven topics; organisation, fitness, competition organisation, minor games, other activities, first aid and liaison with local authorities and other organisations. Some experience of voluntary sports leadership is also required. Some two thousand people have already gained this award, and our readers might know teenagers and others who wish to take the opportunity of learning something of helping the community. Enquiries to: CCPR, Francis House, Francis Street, LONDON SW1P IDE or from any regional CCPR office.

\section{CCPR Warning - Risks in Sport}

Mr. Peter Lawson, the General Secretary, has circulated a memorandum to Governing Bodies of Sport and other member organisations of the CCPR concerning three recent court cases that have implications upon the responsibilities of coaches, teachers, and others supervising sport.

1. AFFUTU.NARTEY v. CLARKE \& ANOTHER, 1984. Clarke, a PE teacher, refereeing a game of Rugby for 15-year-olds, joined in to help out the weaker side, tackled the plaintiff in a violent and unorthodox fashion, leading to a spinal injury. The tackle was held to be unlawful, and the teacher negligent, as he did not take reasonable care to supervise the activity and prevent injury.

2. GIBBS v. BARKING CORPORATION, 1936. A fall from a vaulting horse in the gymnasium led to injury. The court held that the vaulting was inadequately supervised, as reasonable care to prevent a fall had not been displayed.
3. CONDON v. BASI, 1985. A foul tackle in a local soccer league match led to a fractured leg. The tackler had been sent off the field for foul play, and the court awarded damages of $£ 4,900$ against him.

The lessons are that adults should not engage in dangerous play involving the young, that dangerous activities must be supervised properly, and that foul and violent play can lead to injury and subsequent litigation. For any doctor, official, or teacher involved - MAKE ADEQUATE RECORDS AT THE TIME.

\section{Rheumatism and Arthritis}

Lederle Laboratories have issued a lengthy "Press Release" reporting the proceedings of the 16th International Congress of Rheumatology, in Sydney, May, 1985. They have also produced a non-promotional patient information booklet "Arthritis and you - answers to some common questions". This can be obtained by sending a stamped addressed envelope (22 $\times 11 \mathrm{cms}$ minimum - 13p or 17p) to: "Arthritis and You" Booklet Offer, Lederle Laboratories, c/o Alamein Industries, Enham-Alamein, ANDOVER, Hants. SP11 6JS.

This firm has also organised small "workshops" in various centres for GP's to learn and practice techniques of intraarticular injection on life-size joint models. Enquiries to Ms. Alex Ingram, Lederle Laboratories, Fareham Road, GOSPORT, Hants. PO13 OAS

'Clinical Biomechanics' A new quarterly journal is to be published by Messrs. John Wright and Sons Ltd., Techno House, Redcliffe Way, BRISTOL BS1 6NX.

Much of the journal will be devoted to the breakdown in biomechanical stresses that lead to backache and other orthopaedic conditions. The Editorial Board shows the multidisciplinary and multinational approach, and includes many well known to us, such as John Atha, Don Grieve, Duncan Troup, J. P. R. Williams, Gordan MacLellan and Verna Wright - Physicians, Anatomists, Ergonomists, Sports Scientists, and one of the editors, Kim Barton, an Osteopath who has contributed to Brit.J.Sports Med. and read a paper at our Congress '84. Leaflets, and I hope sample inspection copies, will be available at Congress ' 85 .

Price UK $£ 35$, Overseas $£ 40$

'Coaching Focus' This 12 page A4 size leaflet has just been published for the first time by the National Coaching Foundation. No. 1 Spring 1985 is devoted to the problem of doping, with contributions from Prof. Ray Brooks, Ken Kingsbury, Geoff Gleeson, Wilf Paish, Dave Moorcroft, Sir Arthur Gold and Colin Moynihan, MP. The articles, from a range of coaches, a scientist, a physician and a politician, give a well balanced variety, all readable by anyone. The annual subscription is £5 for the two issues each year, from the Sports Council National Coaching Foundation, 'Coaching Focus', 60 Bradford Road, Stanningley, LEEDS LS28 6EF.

\section{Erratum}

In the March issue, BJSM 19:1, we inadvertently made an error in the names of the co-authors, in the paper on metabolic changes following exercise in post-coronary patients, on page 55 and in the Contents page. The third author, correct on page 55 , was incorrectly spelt in Contents - it is D. A. L. WATT, not WALT. The fourth author, misspelt on the camera-ready abstract supplied by the authors as well as in the Contents should be Doreen MILLNS, and not D. MILNE. We offer our apologies to the authors, but these errors emphasise the wisdom of insisting that all co-authors sign the letter accompanying any article legibly. 